\title{
Using Design to Understand Diversity and Inclusion within the Context of the Professional Formation of Engineers
}

\author{
Dr. Carla B. Zoltowski, Purdue University-Main Campus, West Lafayette (College of Engineering)
}

Carla B. Zoltowski is an assistant professor of engineering practice in the Schools of Electrical and Computer Engineering and (by courtesy) Engineering Education, and Director of the Vertically Integrated Projects (VIP) Program within the College of Engineering at Purdue University. She holds a B.S.E.E., M.S.E.E., and Ph.D. in Engineering Education, all from Purdue. Her research interests include the professional formation of engineers, diversity, inclusion, and equity in engineering, human-centered design, engineering ethics, and leadership.

\section{Dr. Andrew O. Brightman, Purdue University at West Lafayette}

Andrew O. Brightman serves as Assistant Head for Academic Affairs and Associate Professor of Engineering Practice in the Weldon School of Biomedical Engineering. His research background is in cellular biochemistry, tissue engineering, and engineering ethics. He is committed to developing effective pedagogies for ethical reasoning and engineering design and for increasing the diversity and inclusion of engineering education.

\section{Prof. Patrice Marie Buzzanell, University of South Florida}

Patrice M. Buzzanell is Professor and Chair of the Department of Communication at the University of South Florida and Endowed Visiting Professor for the School of Media and Design at Shanghai Jiaotong University. Fellow and Past President of the International Communication Association (ICA), she served as President of the Council of Communication Associations and the Organization for the Study of Communication, Language and Gender. She is a Distinguished Scholar of the National Communication Association. Her research focuses on career, work-life policy, resilience, gender, and engineering design. She received ICA's Mentorship Award and the Provost Outstanding Mentor Award at Purdue, where she was University Distinguished Professor and Endowed Chair and Director of the Susan Bulkeley Butler Center for Leadership Excellence. She has worked with Purdue-ADVANCE initiatives for institutional change, four EPICS teams including Transforming Lives Building Global Communities (TLBGC) in Ghana, and individual engineering ethical development and team ethical climate scales as well as everyday negotiations of ethics in design and professional formation of engineers through NSF funding. [Email: pmbuzzanell@usf.edu; buzzanel@purdue.edu]

\section{Dr. Sean Eddington, Kansas State University}

Sean Eddington (Ph.D., Purdue University) is an Assistant Professor of Communication Studies at Kansas State University. Sean's primary research interests exist at the intersections of organizational communication, new media, gender, and organizing. Within engineering contexts, Sean has examined career issues within the engineering discipline regarding (1) new faculty experiences throughout their on-boarding and (2) educational cultures that impact the professional formation of engineers, which was funded by the National Science Foundation. Both projects have been published in the Proceedings of the American Society of Engineering Education. He has also served as a series editor, contributed to trade publications, and facilitated workshops related to higher education administrators' work experiences. Sean is also actively engaged within mentoring activities, and has served as an advisor to multiple student leadership organizations including Beta Theta $\mathrm{Pi}$, which he has received both campus and international awards for his service and mentoring to the Purdue chapter.

\section{Dr. Danielle Corple, Wheaton College}

Danielle Corple is an assistant professor in the Communication Department at Wheaton College, IL. She studies organizational communication, ethics, and diversity and inclusion. 
Memoria Matters is a PhD student in the School of Engineering Education at Purdue University. She is also pursuing a Master's degree at the School of Electrical and Computer Engineering for computer engineering, in which she obtained her BSE from the University of Pennsylvania. Her research interest is in increasing the diversity of engineering by improving the inclusivity of engineering higher education through teaching methods, policies, and culture change.

\section{Ms. Virginia Lynn Booth-Womack, Purdue University at West Lafayette}

Virginia received her B.S. in Industrial Engineering and a B.A. in Psychology while at Purdue University. She is currently the Director of Minority Engineering Programs in the College of Engineering. She assumed the position in 2004 after 18 years of manufacturing experience. Her last assignment was Lean Manufacturing Manager for the for the 3.7L and 4.7L Mack Engine facilities at Chrysler Corporation in Detroit, Michigan. Virginia has applied lean manufacturing concepts to identify and close the achievement gap between under-represented minority engineering students and the total engineering cohort. This was achieved focusing on first semester performance and first year retention through implementation of an aggressive transition program targeting first year engineering students from historically under-represented groups. She recently was called upon to serve as interim Executive Director for the National Society of Black Engineers from December 2013 through August 2014 during which time the organization experienced membership growth and strong metric focus towards goal attainment. 


\section{Using Design to Understand Diversity and Inclusion within the Context of the Professional Formation of Engineers}

\section{Introduction}

Three broad and enduring issues have been identified in the professional formation of engineers: 1) the gap between what students learn in universities and what they practice upon graduation; 2) the limiting perception that engineering is solely technical, math, and theory-oriented; and 3) the lack of diversity (e.g., representation of a wide range of people, thought, and approaches toward engineering) and lack of inclusion (e.g., belonging and incorporating different perspectives, values, and ways of thinking and being in engineering) in many engineering programs. Although these are not new challenges in professional formation, these issues are highly complex, interconnected, and not amenable to simple solution. That is, they are "wicked" problems, which can be best understood and mitigated through design thinking, a human-centered approach based on empathy, ideation, and experimentation [1], as it is a useful perspective for addressing complex and ambiguous issues. Thus, this NSF-funded RFE study utilizes a design thinking approach and research activities to explore foundational understandings of formation and diversity and inclusion in engineering while concurrently addressing three project objectives: 1) To better prepare engineers for today's workforce; 2) To broaden understandings of engineering practice as both social and technical; and 3) To create and sustain more diverse and inclusionary engineering programs.

Although our goal is to eventually study these objectives on a broader disciplinary scale, we began by engaging faculty, students (undergraduate, graduate, and alumni), and staff members within two related, but distinctly different Schools at Purdue University: the School of Electrical and Computer Engineering (ECE) and Weldon School of Biomedical Engineering (BME).

To address the three objectives, we utilized a design thinking approach to develop prototype solutions. Consistent with a design thinking approach, we involved key stakeholders from each department including students, faculty, staff, and administrators, in the research and design process to co-create solutions that addressed our three interrelated objectives in their specific department. The research study was guided by the following questions:

RQ1.How might we make engineering more inclusive?

RQ2. How might we better prepare engineering graduates for practice?

RQ3. How might we use design thinking to address complex issues in engineering education?

In this paper, we provide an overview of the multi-year project and discuss emerging findings and key outcomes from across all phases of the project. Specifically, we will showcase how the research has identified the concurrent ways that understandings of diversity and inclusion are impacted significantly by the local contexts (and cultures) of each department while being compounded by the larger College/University/discipline-wide understandings of who is an engineer and what skills legitimize the identity of "an engineer." 


\section{Background}

A variety of studies have argued that current engineering curricula effectively prepare students for technical and theoretical aspects of engineering as a profession while failing to prepare students for the complex realities of modern workplaces (e.g., complex social environments, teamwork, conflict communication, working in a global workplace) [2]-[5]. This may be because of the singular way that the value and perception of engineering is promoted and reinforced within engineering programs - that is, an explicit focus on engineering as technical and not human-centered or inclusive of alternative positionings of what and who constitutes a successful engineer. Despite change in some engineering discipline profiles and curricular reforms for engineering education, the gender and diversity gap in the student demography of most engineering and computer science departments in universities persists [6]. Although it is important to be "Changing the Conversation" [7], we argue the real need is beyond demographic shifts and one of disciplinary disruption and transformation. That is, engineering itself needs to be constituted as both social and technical such that professional preparation, engineers' identities, and diversity and inclusion are seamlessly integrated throughout.

To make progress towards this goal and achieve change, a dual focus on (1) the local contexts of the ECE and BME departments and the (2) disciplinary culture is necessary for two reasons. First, it is important because the local contexts and the disciplinary cultures mutually reinforce one another as evidenced through values, assumptions, and types of knowledge that are (re)produced [8]. Second, both local and disciplinary cultures provide glimpses into the current and "real" states of everyday experiences and practice of stakeholders within ECE and BME. Understanding these current cultural states is necessary inasmuch as it provides insights into the changes that are needed to improve cultural states [8]. Taking a culture-centered approach can create opportunities for both sustainable and widespread change efforts--particularly in professional formation contexts and within engineering education. To enact cultural change, it is vital to shed light on/illuminate the hidden assumptions, the taken-for-granted values, beliefs, and norms that govern and guide individuals within a culture [8].

Furthermore, unpacking engineering's core values and assumptions of engineering identity provide an opportunity for engineering educators to create more inclusive environments. Students' experiences of engineering within their undergraduate education shape their understanding of the nature of the work done by engineers, the skills and knowledge that are valued and needed in engineering, and whether these things align with their personal identity and values.

\section{Project Overview}

Our project is organized around the three phases of the design process (inspiration, ideation, and implementation), and embedded within the design process is a longitudinal, multiphase, mixedmethods study (Figure 1). 
Figure 1. Design Thinking Process adapted from IDEO [9]
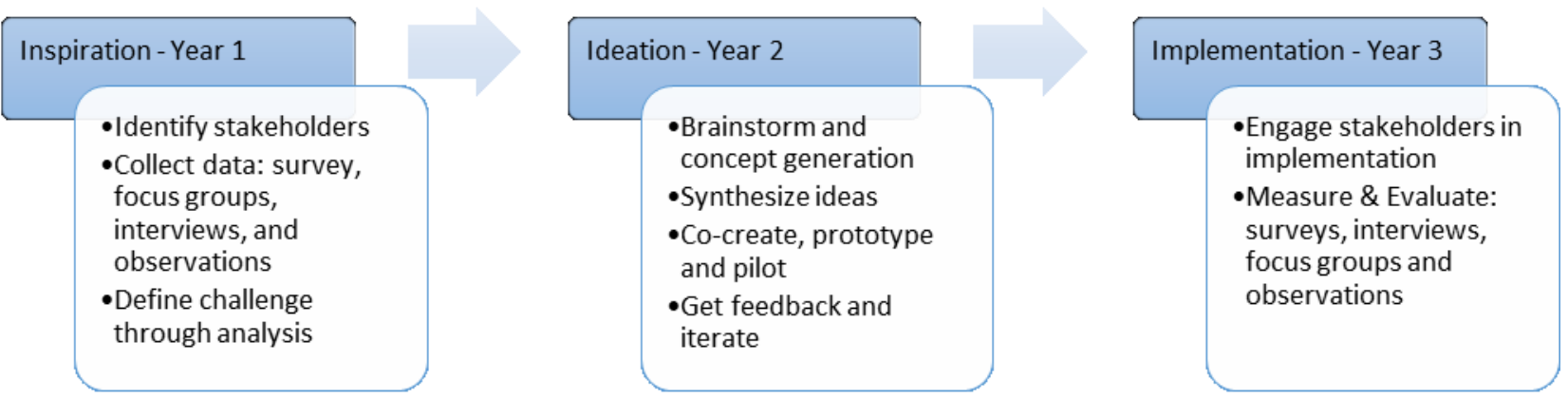

A summary of the project data collection by design phase and stakeholder group is given in Table 1. In Year One, we implemented activities of the Inspiration Phase which included collecting and analyzing survey, interview, and observation data from a broad set of stakeholders which included faculty, staff, and administrators and students (undergraduate and graduate) in both ECE and BME departments. During Year Two, the Ideation phase, we facilitated design sessions with faculty, staff, and students from each of the two departments to investigate underlying issues and then to develop prototypes related to diversity and inclusion and professional formation. During the Implementation phase, in Year Three, we worked with BME and ECE stakeholders to further define and develop the prototypes. Additionally, we continued to assess stakeholders' understanding of the effectiveness of design thinking toward organizational change in both departments.

\begin{tabular}{|c|c|c|}
\hline Design Phase & Students & Faculty/Staff/Admin (FSA) \\
\hline Inspiration & $\begin{array}{l}\text { - Surveys (N=31 BME \& } 134 \\
\text { ECE) } \\
\text { - Interviews (N=12 ECE, } \\
\mathrm{N}=18 \text { BME) } \\
\text { - Observations (N=3 ECE; } \\
\mathrm{N}=2 \text { in BME) }\end{array}$ & $\begin{array}{l}\text { - Interviews ( } \mathrm{N}=13 \mathrm{ECE}, \mathrm{N}=16 \mathrm{BME}) \\
\text { - Observations }\end{array}$ \\
\hline Ideation & \multicolumn{2}{|c|}{$\begin{array}{l}\text { - Brainstorming } \\
\text { - Co-creation/prototyping sessions for both solution and implementation } \\
\text { - Informal and Formal Feedback Sessions }\end{array}$} \\
\hline $\begin{array}{l}\text { Implementation } \\
\text { (ongoing) }\end{array}$ & $\begin{array}{l}\text { - Interviews ( } \mathrm{N}=20 \mathrm{ECE} \\
\mathrm{N}=16 \mathrm{BME}, 5 \text { other) } \\
\text { - Evaluation of the process } \\
\text { - Observations }\end{array}$ & $\begin{array}{l}\text { - Interviews ( } \mathrm{N}=15 \mathrm{ECE}, \mathrm{N}=15 \mathrm{BME} \text { ) } \\
\text { - Evaluation of the process } \\
\text { - Observations }\end{array}$ \\
\hline
\end{tabular}

Table 1. Data Collection by Design Phase and Stakeholder Group

\section{Findings}

Our research team has conducted several analyses that, together, are providing insight to the disciplinary, department, and university cultures that underlie the interconnected issues related to professional formation, integrated socio-technical understands of engineering, and diversity and inclusion. Furthermore, the analyses are revealing how those cultures can shape the ways in 
which design thinking can be used as an effective strategy for addressing these wicked problems of social dynamics and organizational change. In the following sections, we briefly describe the context of these analyses and summarize the findings.

Students' experiences regarding and understanding of diversity and inclusion are impacted by the disciplinary ecosystem of Electrical and Computer Engineering (ECE).

Using a constant-comparative method, we analyzed interviews from 18 current or former ECE students to uncover students' understandings of the disciplinary culture of ECE and to better understand their how diversity and inclusion is experienced within the ECE department. Using the findings from the interviews, observations were conducted with three current ECE students to further understand their experiences in ECE. The findings indicated that the support for diversity and inclusion within the ECE department is often constrained and limited as a result of the prevailing macrosystemic values (e.g., masculine ideals of who and what counts in ECE; see [10]) within the department. These values minimize the importance of not only those diversity and inclusion initiatives in the department, but also those across the university [11].

\section{The disciplinary culture of BME promotes independence and individuality as norms for student success, and students require different forms of capital (e.g., social, cultural, and navigational) to be successful.}

This case study examined the culture of the BME department and its underlying assumptions regarding what sources of cultural and social capital undergraduate students need to be successful. Through interviews with 18 current or former BME students, we examined norms of teaching and learning in the BME disciplinary culture, discovering that students perceived the BME culture as reinforcing highly independent strategies for learning and professional development. More specifically, students perceived they were 'on their own' in: (a) developing a specialty in a BME subfield to be marketable upon graduation, (b) learning course content by teaching themselves, and (c) finding and pursuing professional development opportunities. As a result, students drew on resources outside of the program such as family and peer social networks, high school training in STEM subjects, and other forms of social and cultural capital. As under-represented minority (URM) students and first-generation college (FGC) students are less likely to possess these forms of capital [12]-[14], this finding suggests that BME cultures may raise barriers to URM and FGC student [15].

\section{The disciplinary cultures of the ECE and BME departments impact the effectiveness of the design thinking process.}

Analysis of the post-design session interviews revealed the impact that the disciplinary and organizational cultures of both ECE and BME impacted (1) the effectiveness of design thinking toward culture change, and (2) the space in which change occurred (e.g., individual versus systemic levels). Reflecting a more limited design culture within the school, the stakeholders in the ECE design sessions recognized and acknowledged limitations in their ability to make largescale change within ECE. As such, prototypes developed by ECE stakeholders from the design thinking sessions addressed interactional and day-to-day issues that faculty, staff, and students face pertaining to diversity and inclusion. However, because they were issues that the 
stakeholders had the power to enact, progress has been made. On the other hand, the stronger design culture of BME (compared with ECE) was reflected by the recognition of both the need and the ability to address large-scale, macro-level diversity and inclusion issues within the school (e.g., defining the organizational identity of BME; redefining recruitment practices and protocols to address different populations that were missing from the BME student population), as well as structural issues at the university level. However, it has also been difficult to see significant changes immediately with regards to these macro-issues identified by the BME stakeholders [16]-[18].

\section{ECE faculty's attitudes and perception of behavior control and norms all impact change related to diversity and inclusion.}

Using the model for intention given by Fishbein and Ajzen's theory of reasoned action [19], we analyzed the ECE faculty interviews to identify themes which represent opportunities for, or barriers to, improved diversity and inclusion in the department. The core idea of the reasoned action model is that any behavior is directly predicted by an intention to perform that behavior, and that intention is created through three main factors: attitude, perceived norm, and perceived behavioral control. Within this study, the three factors necessary for intention could be rephrased from faculty's perspective as "I care about this" (attitude), "I should do something about it" (perceived norm), and "I can do something about it" (perceived behavioral control). Without any one of these factors, faculty can justify not taking action; they turn into "It doesn't matter," "It's not my job," or "There's nothing I can do." The interviews revealed that 1) department leadership's visible support was a notable influence on faculty's development of a positive attitude toward diversity and inclusion; 2) faculty deemphasized their roles as teachers because of a perceived norm to prioritize research, which originated from cultural values of the department; and 3) that faculty perceived a lack of behavioral control over diversity and inclusion. The study found that, to see effective, sustainable change, attitude, perceived norm and perceived behavioral control must be addressed together, and failure to do so could not only be ineffective but contribute to more negative attitudes towards diversity and inclusion [20].

\section{Conclusions and future work}

Our research has identified ways in which student and faculty understandings of diversity and inclusion are impacted significantly by the local contexts of their school and compounded by the larger college, university, and discipline-wide understanding of who is an engineer and what skills legitimize the identity of "an engineer." Currently, we are developing strategies for using design thinking in social change research that could be implemented by other academic programs to address complex issues in their departments. In addition, we have initiated a new phase of post-study interviews of engineering students and faculty members. In this phase, students and faculty are being interviewed and analyzed to understand the impact of this NSF project.

\section{Acknowledgements}

This work was made possible by grants from the National Science Foundation (EEC-1636446) and Purdue University. Any opinions, findings, and conclusions or recommendations expressed 
in this material are those of the authors and do not necessarily reflect the views of the National Science Foundation or Purdue University.

\section{References}

[1] IDEO U, "What is Design Thinking?" [Online]. Available: https://www.ideou.com/blogs/inspiration/what-is-design-thinking [Accessed: May 1, 2020].

[2] S. Brunhaver, R. Korte, S. Barley, and S. Sheppard, "Bridging the gaps between engineering education and practice," in Engineering in a Global Economy, R. Freeman and H. Salzman, Eds. Chicago: Chicago University Press, 2018, pp. 129-165.

[3] C. Carrico, K. Winters, S. Brunhaver, and H. M. Matusovich, "The pathways taken by early career professionals and the factors that contribute to pathway choices," Proceedings of the 2012 American Society for Engineering Education Annual Conference \& Exposition, San Antonio, TX., June 2012.

[4] C. J. Atman, S. D. Sheppard, J. Turns, R. S. Adams, L. N. Fleming, R. Stevens, R. A. Streveler, K. A. Smith, R. L. Miller, L. J. Leifer, K. Yasuhara, and D. Lund. Enabling Engineering Student Success: The Final Report for the Center for the Advancement of Engineering Education. San Rafael, CA: Morgan \& Claypool Publishers, 2010.

[5] J. Trevelyan, “Technical coordination in engineering practice," Journal of Engineering Education, vol. 96, pp. 191-204, 2007.

[6] J. Roy, "Engineering by the numbers (2018)," 2019. Retrieved from https://ira.asee.org/by-the-numbers/.

[7] National Academy of Engineering. 2008. Changing the Conversation: Messages for Improving Public Understanding of Engineering. Washington, DC: The National Academies Press. https://doi.org/10.17226/12187.

[8] E. Godfrey, "Understanding disciplinary cultures: The first step to cultural change." In A. Johri \& B. Olds (Eds.), Cambridge Handbook of Engineering Education Research, pp. 437-456, New York, NY: Cambridge University Press, 2014.

[9] “Join us for Design Kit: Prototyping," Design Kit. [Online]. Available: http://www.designkit.org/. [Accessed: 21-Mar-2019].

[10] B. Jesiek, and L. Jamieson, L, "The expansive (dis)integration of electrical engineering education," IEEE Access, pp. 4561-4573, 2017. [Online]. Available: http://ieeexplore.ieee.org/abstract/document/7869378/ [Accessed: May 1, 2020].

[11] S. M. Eddington, C. B. Zoltowski, A. O. Brightman, R. Joshi, P. M. Buzzanell, and D. Torres, "Diversity and Inclusion in Engineering: Students' Perceptions of Learning and Engaging with Difference." In Proceedings of the 2018 ASEE Annual Conference. 2018. 
[12] J. P. Martin, M. K. Miller, and D. R. Simmons, "Exploring the theoretical social capital 'deficit' of first generation college students: Implications for engineering education," International Journal of Engineering Education, vol. 30, no. 4, pp. 822-836, 2014.

[13] J. M. Trenor, S, L. Yu, C. L. Waight, and K. S. Zerda, "Influences for selecting engineering: Insights on access to social capital from two case studies," Proceedings of the 38th Annual Frontiers in Education Conference, Sarasota Springs, NY, 2008.

[14] J. P., Martin, D. R. Simmons, and S. L. Yu, " The role of social capital in the experiences of Hispanic women engineering majors," Journal of Engineering Education, vol. 102, pp. 227-243, 2013.

[15] D. Corple, C. B. Zoltowski, S. M. Eddington, A. O. Brightman, and P. M. Buzzanell, "What You Need to Succeed: Examining Culture and Capital in Biomedical Engineering Undergraduate Education." In ASEE annual conference \& exposition proceedings. 2019.

[16] S. M. Eddington, C. B. Zoltowski, A. O. Brightman, D. Corple, and P. M. Buzzanell, Tensions in Applying a Design-Thinking Approach to Address Barriers to Increasing Diversity and Inclusion in a Large, Legacy Engineering Program.” ASEE Annual Conference \& Exposition Proceedings, June 2019.

[17] S. M. Eddington, D. Corple, P. M. Buzzanell, C. Zoltowski, and A. Brightman,, "Organizing Design for Organizational Culture Change in Engineering," presented at the $69^{\text {th }}$ Annual International Communications Association Conference, Washington, D.C., May 2019.

[18] R. Joshi, C. B. Zoltowski, A. O. Brightman, S. Eddington, P. M. Buzzanell, and D. Torres, "Evaluating the Impact of Design Sessions on Participants' Perceptions of Diversity and Inclusion in the Professional Formation of Biomedical Engineers," Proceedings of the 2018 ASEE Annual Conference, Salt Lake City, UT, June 2018.

[19] M. Fishbein and I. Ajzen, Predicting and Changing Behavior: The Reasoned Action Approach. New York, NY: Psychology Press, 2010.

[20] M. E. Matters, C. B. Zoltowski, A. O. Brightman, and P. M. Buzzanell, “An engineering faculty and an intention to make change in diversity and inclusion: Creating sustainable change efforts," to be presented at the CoNECD - The Collaborative Network for Engineering and Computing Diversity, Crystal City, Virginia, Jan. 2021. 